\title{
A intersetorialidade como estratégia de implementação de políticas públicas
}

\author{
Luana Cristina Baldo*, Luiz Carlos Lückmann** \\ *Secretaria Municipal de Saúde, Capinzal, SC, Brasil. **Programa de P-G em Educação, UNOESC, Joaçaba, SC, Brasil.
}

\section{Resumo}

O texto analisa a intersetorialidade e sua interface com a educação na articulação de programas de assistência social. As políticas sociais no Brasil tem sido criadas e implementadas de forma setorizada e desarticulada, tornando-se, quase sempre, ineficazes. Experiências, contudo, mostram que é possível trabalhar intersetorialmente, integrando programas de governo em parceria com municípios e sociedade, como é o caso do trabalho realizado nos municípios da $7^{\mathrm{a}}$ Gerência Regional de Educação, SC, Brasil. O estudo revelou serem perceptíveis as conquistas decorrentes da adoção de políticas intersetoriais no campo da educação, sobretudo as que possuem interfaces com a saúde e assistência social.

Palavras-chave: políticas públicas, intersetorialidade, educação, programas sociais.

\section{Considerações iniciais}

A intersetorialidade tem sido objeto de estudos e instrumento de políticas de governos há pelo menos duas décadas, contudo, ficam limitados a ações isoladas e descontinuadas, sem que se traduzam em políticas de Estado. Exemplos podem ser buscados no campo da saúde, da assistência social e da educação.

O presente texto analisa a intersetorialidade a partir das políticas educacionais, tomando-se como referência a experiência em andamento na $7^{\text {a }}$ Gerência Regional de Educação do Estado de Santa Catarina, Brasil. Mais especificamente, deseja-se aprofundar conceitos/visões que se tem sobre a intersetorialidade e como esta pode permear as políticas públicas, em especial, a educação.

Em função da natureza do estudo, fez-se a opção pela pesquisa qualitativo-exploratória, intercalando o uso de fontes documentais, bibliográficas e de pessoas.

\section{Iintersetorialidade e políticas públicas}

As políticas sociais ganham relevância mundial no cenário do pós Guerra Fria para suprir duas necessidades: uma decorrente das condições subhumanas às quais milhões de pessoas tiveram que se submeter após a II Guerra Mundial; a outra por conta da intensificação do capitalismo mundial, cujos resultados acentuaram ainda mais as desigualdades sociais. Essa realidade levou à criação de um novo modelo de Estado, que veio a chamar-se de WelfareState (Estado do Bem Estar Social), com o papel de promover e implementar políticas sociais como forma de aliviar as chagas sociais deixadas pela guerra.

No Brasil, a ampliação das políticas sociais veio mais tarde, no contexto do processo de redemocratização do país, culminando com a promulgação da Constituição Federal de 1988. Entretanto, observa-se que, quase sempre, as políticas sociais são criadas e implementadas na sociedade brasileira de forma fragmentada e desarticulada, tornando-se, por conta disso, não raramente ineficazes.

Tal prática é herança de um paradigma de sociedade espelhado no cientificismo, cujos resultados produzem a fragmentação da ciência em especialidades e disciplinas. Esse fenômeno contaminou todas as áreas do conhecimento, entre elas a área das políticas sociais.

Tumelero (2014, p. 5-6), já havia chamado a atenção às consequências que isso poderia acarretar junto aos usuários dos serviços públicos. Segundo a autora: “[...] a estrutura segmentada dos governos em saberes e conhecimentos setorizados e especializados tem efeitos sobre os usuários dos serviços públicos, os quais não são percebidos como integrantes de uma realidade de múltiplas determinações que também inclui aspectos subjetivos.”

A alternativa que se tem buscado para enfrentar a fragmentação teórica e prática na área das políticas públicas está no desafio do trabalho intersetorial. Inojosa (2001, p. 105) entende a intersetorialidade como a "articulação de saberes e experiências com vistas ao planejamento, para a realização e a avaliação de políticas, programas e projetos, com o objetivo de alcançar resultados sinérgicos em situações complexas.” Trabalhar na perspectiva da intersetorialidade significa, portanto, buscar a sinergia entre as políticas e programas sociais com o objetivo de buscar e alcançar resultados qualitativamente melhores e mais eficazes.

Para Monnerat e Souza (2009, p. 205): “A intersetorialidade constitui uma nova forma de gerenciar as cidades, ou seja, é uma proposta de modelo de gestão urbana. Aqui está presente a preocupação com a questão da otimização de recursos humanos e financeiros, considerada como mais uma virtude das ações intersetoriais, visto que contribuiria para combater a ineficácia das políticas sociais.” Como se observa, a intersetorialidade é de interesse não só dos profissionais das políticas públicas que se deparam com as situações complexas da realidade social, mas também da administração pública.

Algumas experiências em andamento mostram que é possível trabalhar na perspectiva da 
intersetorialidade, integrando programas e ações de governo em parceria com os municípios e a sociedade, como, por exemplo, aqueles programas que dizem respeito à política de assistência social.

No Brasil, o Programa Bolsa Família foi pioneiro nessa questão. Apesar da distribuição de renda ser seu principal objetivo, existem outras condicionalidades nas áreas da saúde e da educação para o recebimento do benefício. Houve, recentemente, todo um processo de capacitação dos sujeitos envolvidos, no sentido de orientá-los no desenvolvimento de ações integradas entre essas políticas públicas, indo além do trabalhado desenvolvido por cada política.

A própria Política Nacional de Assistência Social orienta para que o trabalho nessa área seja desenvolvido na lógica da intersetorialidade das ações, quando diz: "Os serviços, programas, projetos e benefícios de proteção social básica deverão se articular com as demais políticas públicas locais, de forma a garantir a sustentabilidade das ações desenvolvidas e o protagonismo das famílias e indivíduos atendidos, de forma a superar as condições de vulnerabilidade e a prevenir as situações que indicam risco potencial.” (BRASIL, 2005, p. 34-35).

O Programa de Acompanhamento e Monitoramento do Acesso e Permanência na Escola das Pessoas com Deficiência - Programa BPC na Escola é outro exemplo decorrente dessa política. Tem por finalidade integrar ações envolvendo educação, saúde, assistência social e direitos humanos, com o objetivo de incluir nas escolas regulares crianças e adolescentes que recebem o Benefício de Prestação Continuada da Assistência Social.Trata-se de uma iniciativa de inclusão de crianças e adolescentes com eficiência, através da identificação e superação das barreiras encontradas no acesso à escola.

A Norma Operacional Básica do Sistema Único de Assistência Social, em seu artigo $3^{\circ}$ (BRASIL, 2012), define alguns princípios de ação, entre eles, o princípio da intersetorialidade, cujo conceito tem a ver com "integração e articulação da rede socioassistencial com as demais políticas e órgãos setoriais” (2012, p.16). Por conta dessa orientação, os municípios têm procurado organizar reuniões e encontros com a rede socioassistencial das políticas públicas, com o objetivo de debater questões pertinentes aos atendimentos de cada instituição e buscar soluções conjuntas para problemas vivenciados pelas mesmas.

Na política de saúde, a Lei $\mathrm{n}^{\circ}$ 8.080, de 1990, em seu artigo 12, prevê a criação de comissões intersetoriais em âmbito nacional e especifica, em seu parágrafo único, que: “As comissões intersetoriais terão a finalidade de articular políticas e programas de interesse para a saúde, cuja execução envolva áreas não compreendidas no âmbito do Sistema Único de Saúde (SUS).” Há, portanto, a previsão de ações intersetoriais.

Uma das iniciativas desenvolvidas nessa área é o Programa Saúde na Escola, cujo objetivo é o de integrar ações de promoção, prevenção e atenção à saúde. A Nota Técnica Conjunta $n^{\circ}$ 56/2014 do
Ministério da Educação assim se manifesta: $O$ Programa Saúde na Escola “[...] é fruto do esforço do Governo Federal em construir políticas intersetoriais para a melhoria da qualidade de vida da população brasileira [...]”. O Programa é uma estratégia intersetorial entre o Ministério da Saúde e o Ministério da Educação, com o objetivo de promover a atenção integral à saúde dos estudantes da rede pública de educação básica por meio das ações de promoção, prevenção e atenção à saúde. (MS, 2014).

Entre as ações, o Programa Saúde na Escola avalia a saúde do educando, assim como o acompanhamento, atividades de prevenção e capacitação dos profissionais da educação. Como se observa, as demandas de saúde perpassam a educação, tais como as questões relacionadas à nutrição da criança e do adolescente, drogas, doenças sexualmente transmissíveis, gravidez na adolescência. São questões que merecem atenção das políticas públicas de forma integrada.

Embora a intersetorialidade no campo da educação seja algo relativamente novo, o Ministério da Educação tem pactuado e participado de programas de outras áreas, uma vez que os processos de ensinoaprendizagem implicam numa série de outras questões, entre elas a família, a saúde, a violência, a renda, etc. Isoladamente, não há como dar respostas a todas essas questões. Monnerat e Souza (2009, p. 206-207) fazem menção a essa necessidade de articulação: “A necessidade de articulação se evidencia com a persistência de indicadores negativos quanto à evasão escolar, altas taxas de analfabetismo, disparidade na relação idade e série, dentre outras questões. Assim, o olhar da Educação sobre a intersetorialidade tem como base o reconhecimento de que os problemas estruturais que afetam as famílias repercutem diretamente nas condições de aprendizagem das crianças e adolescentes."

Apesar das iniciativas intersetoriais serem fundamentadas em demandas reais das políticas públicas e os programas partirem dos ministérios e secretarias estaduais, as ações são realizadas nos municípios. Por conta dessa práxis, alguns questionamentos são colocados. Qual é, por exemplo, a percepção que os municípios e seus agentes possuem dessas políticas? Como esperar resultados de ações decorrentes de políticas intersetoriais que são formuladas centralizadamente e executadas de forma descentralizada? Essas e outras questões foram examinadas a partir de experiência em andamento junto às Secretarias de Educação dos Municípios da $7^{\text {a }}$ Gerência Regional de Educação do estado de Santa Catarina.

\section{Método}

Para tanto, ouviu-se os profissionais da educação que atuam em programas intersetoriais dos treze municípios que compõem a Gerência Regional. O instrumento com as questões foi encaminhado às 
pessoas responsáveis por programas intersetoriais junto às escolas, fazendo-se uso da ferramenta Google Forms. Obteve-se o retorno de doze municípios.

O questionário foi respondido por profissionais de nível superior na área educacional. Participaram da pesquisa uma secretária, três secretárias escolares, duas diretoras, uma professora de sala de AEE, uma coordenadora pedagógica, uma supervisora educacional, uma diretora de educação, um agente administrativo e uma secretária municipal de educação.

\section{Ações intersetoriais em andamento}

A primeira questão teve o propósito de conhecer quais eram os programas trabalhados intersetorialmente pelos municípios no campo da educação. Todos os municípios afirmaram estar participando de, pelo menos, um programa intersetorial. Logo, possuem alguma experiência em projetos e ações intersetoriais no campo educacional, apesar de esta ser uma política relativamente nova no país.

O Programa com maior participação intersetorial pelos municípios é o Bolsa Família (100\%). Nessa parceria, cabe à Secretaria de Educação repassar ao Programa a frequência escolar dos alunos cujas famílias recebem o benefício. Apesar de esta ser atribuição burocrática, vincular $\mathrm{o}$ benefício do Programa à frequência escolar atende importante objetivo, que é o de garantir o acesso e permanência das crianças dessas famílias na escola, como política de superação da pobreza, uma vez que os baixos níveis de escolaridade estão diretamente ligados à renda familiar. Sabe-se, igualmente, que os problemas da frequência escolar e da própria evasão estão relacionados a questões que necessitam de atuação intersetorial, envolvendo, por exemplo, a área da saúde e da assistência social, contemplados nas condicionalidades do Programa Bolsa Família.

Para Agatte e Ximenes (2011, p. 12): "Pretende-se com as condicionalidades reforçar o acesso das famílias beneficiárias às políticas de educação, saúde e assistência social, promovendo melhoria das condições de vida, bem como levar o poder público a assegurar a oferta desses serviços. O adequado acompanhamento das condicionalidades possibilita a identificação de situações de vulnerabilidades no contexto familiar que interfiram no acesso aos serviços básicos a que as famílias têm direito, demandando ações do poder público no atendimento a essas situações.”

Outros Programas com significativa adesão pelas Secretarias Municipais de Educação são o Programa Benefício de Prestação Continuada na Escola - BPC (92\%), o Programa Saúde na Escola - PSE (29\%) e o Atendimento Socioeducativo (92\%). Ainda com percentual expressivo em termos de adesão pelos municípios aparecem as reuniões da rede municipal de atendimento e garantia de direitos, uma iniciativa dos municípios que tem como objetivo a troca entre os profissionais das diferentes políticas públicas.

A segunda questão dirigida aos sujeitos de pesquisa teve como objetivo avaliar a participação dos profissionais envolvidos nos programas e ações intersetoriais em andamento. Entendeu-se ser importante a avaliação, vez que a maioria dos programas implementados são concebidos e formulados como macropolíticas governamentais, sem a participação dos municípios.

Todos os profissionais da educação que responderam ao questionário afirmaram ser importante trabalhar intersetorialmente. Pode-se inferir que a adesão a programas intersetoriais se torna uma necessidade aos municípios, uma vez que, por meio deles, recebem recursos financeiros. De outro lado, as escolas se veem impotentes na solução de alguns problemas, pois estes somente podem ser solucionados quando elas se aproximarem de outras políticas públicas. Segundo Oliveira (2012, p. 15): “[...] Nesse contexto, a intersetorialidade assume o significado de potencialização das ações e ocorre a partir da integração intencional do Sistema Educacional com os Sistemas de Saúde, de Assistência Social, do Poder Judiciário, entre outras instituições que possam, a partir das necessidades identificadas no cotidiano escolar, contribuir com o fortalecimento da "armadura dos direitos de cidadania” dos alunos das instituições escolares.”

Para que seja garantido às crianças o direito à educação e, consequentemente, à cidadania, a escola é o primeiro passo. Alguns programas intersetoriais têm esse objetivo, como é o caso do Programa Bolsa Família e o BPC na Escola. Crianças oriundas de uma realidade de baixa renda familiar ou com dificuldades de aprendizagem terão, na escola e nos programas intersetoriais que com a escola interagem, maiores oportunidades de superação dessa realidade.

\section{Desafios frente às dificuldades}

Considerar um trabalho importante não significa dizer, em sua execução, que não existam entraves e dificuldades para alcançar os seus objetivos. Uma das questões dirigidas aos profissionais participantes desse estudo teve como escopo as dificuldades encontradas no desenvolvimento das ações intersetoriais.

As políticas públicas desenvolvidas intersetorialmente requerem planejamento, uma vez que os programas e ações necessitam adequar-se à realidade de cada município. Isso somente será possível com o diálogo entre os profissionais, tanto para planejar, quanto para dar andamento ao trabalho e avaliá-lo.

Os profissionais que participaram desse estudo demonstraram encontrar algum nível de dificuldade em relação ao planejamento das ações (34\%). Ou seja, 
apesar do acúmulo de responsabilidades inerentes ao trabalho docente, somadas às responsabilidades exigidas pelos programas intersetoriais, os profissionais indicam ser possível planejar e dialogar com outras políticas públicas.

A mesma questão respondida pelos profissionais também aponta para a dificuldade de chegar-se ao consenso das ações a serem realizadas (34\%), dada a diversidade de visões na hora de planejálas. Há uma tendência de considerar-se mais importante aqueles programas com os quais os profissionais mais se identificam. Trabalhar intersetorialmente exige conformidade de opiniões, visando-se objetivos comuns. Outras dificuldades foram identificadas nas respostas dos sujeitos de pesquisa, tais como: diálogo entre as políticas públicas (25\%) e definição de prioridades (25\%).

\section{Avanços e conquistas}

A última questão dirigida aos participantes desse estudo teve o objetivo de avaliar os programas intersetoriais assumidos pelos municípios. Foi assim formulada: a partir de sua experiência de trabalho com as demais políticas públicas, você visualiza algum avanço ou conquista para a política de educação através do trabalho intersetorial?

Pelas respostas, são perceptíveis os avanços e conquistas propiciados pela adoção de políticas intersetoriais no campo da educação. Metade do grupo (50\%) visualizou muitos avanços, revelando a importância desse trabalho desenvolvido pelos profissionais da educação em conjunto com as demais políticas públicas do seu município. Outros 41,67\% entenderam haver alguns avanços e 8,33\% manifestaram haver poucos avanços.

A questão permitiu que os profissionais pudessem relatar quais avanços/conquistas resultaram desse trabalho. Destacam-se algumas falas: vínculo entre família, instituição e comunidade; direito à aprendizagem; redução da evasão escolar; melhores condições de saúde; atendimento com profissionais (psicólogos, terapeutas) para os membros da família; reuniões para discutir problemas sociais da Rede. Um dos respondentes observa, em particular: “com o envolvimento intersetorial todas as crianças são atendidas em suas necessidades".

Os resultados colhidos dos profissionais participantes desse estudo mostram haver integração dos Sistemas de Assistência Social, do Sistema Único de Saúde e do Sistema Educacional. Para Oliveira (2012, p. 14) “[...] Tal integração dos Sistemas e Espaços Institucionais só pode ocorrer a partir da institucionalização do trabalho intersetorial. Um efeito desse trabalho pode ser a melhoria das ações educacionais na escola e, assim, a melhoria da qualidade na educação, dado que pode contribuir com a resolução dos problemas sociais que tanto interferem negativamente no processo de ensino e de aprendizagem quanto extrapolam a capacidade resolutiva da instituição escolar.”
Para avançar, é preciso ir além das obrigações que os programas colocam. Ou seja, a intersetorialidade deve fazer parte do cotidiano do trabalho das instituições; não pode ser vista como mais uma obrigação/atribuição. E a educação tem muito a ganhar em qualidade.

\section{Considerações finais}

Como os resultados revelaram, há uma tendência de a educação abrir-se ao trabalho intersetorial em conjunto com as demais políticas públicas, em especial aquelas que possuem interfaces mais próximas, como saúde e assistência social.

Sabe-se que o trabalho intersetorial entre educação e outras políticas públicas ainda fica restrito a poucas experiências, em geral, em regiões do país com estruturas educacionais mais avançadas. Enquanto regiões buscam a intersetorialidade, outras sofrem com a falta de condições estruturais básicas dentro das escolas. Ou seja, as desigualdades regionais dificultam a implementação de iniciativas inovadoras.

Os avanços verificados no estudo reforçam a ideia de que a intersetorialidade entre educação e outras políticas públicas é possível, desde que haja a estrutura necessária, inclusive de pessoal, o planejamento e a vontade política de querer fazer acontecer. O estudo revelou, ainda, que os profissionais da educação estão abertos a novas experiências que contribuam para uma educação de maior qualidade.

\section{REFERÊNCIAS}

AGATTE, J. P; XIMENES, D. A. A gestão das condicionalidades do Programa Bolsa Família: uma experiência intersetorial e federativa. Inc. Soc., Brasília, DF, v. 5, n. 1, p.11-19, jul./dez. 2011. Disponível em:

$<$ http://revista.ibict.br/inclusao/index.php/inclusao/art icle/viewFile/234/196>. Acesso em: 27 fev. 2015.

BRASIL. Lei n. 8.080, de 19 de setembro de 1990.

Dispõe sobre as condições para a promoção, proteção e recuperação da saúde, a organização e o funcionamento dos serviços correspondentes e dá outras providências. Diário Oficial da União, Brasília, DF, 20 set.1990. Disponível em: $<$ http://www.planalto.gov.br/ccivil_03/leis/18080.htm LEI 8.080>. Acesso em: 2 dez. 2014.

. Resolução no 33, de 12 de dezembro de 2012.

Aprova a Norma Operacional Básica do Sistema Único de Assistência Social -NOB/SUAS. Diário Oficial da União - DOU. Brasília, DF, 2013.

Nota Técnica Conjunta n ${ }^{0}$ 56, de 21 de março de 2014. Ministério da Saúde. Brasília, DF, 2014. . Resolução n ${ }^{0} 145$, de 15 de outubro de 2004. Estabelece a Política Nacional de Assistência Social - PNAS. Diário Oficial da União - DOU. Brasília, DF, 28 out. 2004.

INOJOSA, R. M. (2001). Sinergia em Políticas e Serviços Públicos: desenvolvimento social com 
intersetorialidade. Cadernos FUNDAP, PUC, SP, n. 22, 2001, p. 102-110. Disponível em:

$<$ htpps://www.pucsp.br/prosaude/.../sinergia_politica s_servicos_publicos.pdf. Acesso em: 2 dez. 2014.

MONNERAT, G. L. \& SOUZA, R. G. de. (2009).

Política Social e Intersetorialidade: consensos teóricos e desafios práticos. SER Social, Brasília, v. 12, n. 26, p. 200-220, jan./jun. 2009.

OLIVEIRA, R. C. (2012). Intersetorialidade entre as políticas públicas e seus efeitos na escola pública brasileira. Ata do Congresso Internacional de Pedagogia Social, 2012, São Paulo (SP, Brasil) [online]. Disponível em: <http://www.proceedings.scielo.br/scielo.php?script=sc i_arttext\&pid=MSC0000000092012000200024\&lng =en\&nrm=iso $>$. Acesso em: 4 dez. 2014.

TUMELERO, S. M. (2014). Intersetorialidade nas políticas públicas. Disponível em: <http://pt.scribd.com/doc/244650788/TUMELEROSILVANA-Intersetorialidade-Cong-Chile-pdf $>$. Acesso em: 2 dez. 2014. 